\title{
Protection by Panax ginseng C.A. Meyer against the genotoxicity of doxorubicin in somatic cells of Drosophila melanogaster
}

\author{
Denise G. Pereira ${ }^{1}$, Lusânia M.G. Antunes ${ }^{2}$, Ulrich Graf ${ }^{3}$ and Mário A. Spanó ${ }^{1}$ \\ ${ }^{1}$ Laboratório de Mutagênese, Instituto de Genética e Bioquímica, Universidade Federal de Uberlândia, \\ Uberlândia, MG, Brazil. \\ ${ }^{2}$ Departamento de Análises Clínicas, Toxicológicas e Bromatológicas, Faculdade de Ciências \\ Farmacêuticas de Ribeirão Preto, Universidade de São Paulo, Ribeirão Preto, SP, Brazil. \\ ${ }^{3}$ Physiology and Animal Husbandry, Institute of Animal Sciences, ETH Zurich, Schwerzenbach, Switzerland.
}

\begin{abstract}
Panax ginseng is one of the most widely prescribed herbal medicines for the treatment of cancer, diabetes, chronic inflammation, and neurodegenerative and cardiovascular diseases. Since the use of alternative medicines in combination with conventional therapy may increase the risk of unwanted interactions, we investigated the possible genotoxicity of a water-soluble form of the dry root of $P$. ginseng $(2.5,5.0$ or $10.0 \mathrm{mg} / \mathrm{mL})$ and its ability to protect against the genotoxicity of doxorubicin (DOX; $0.125 \mathrm{mg} / \mathrm{mL}$ ) by using the Drosophila melanogaster wing somatic mutation and recombination test (SMART) with standard and high-bioactivation crosses of flies. Panax ginseng was not genotoxic at the concentrations tested, whereas DOX-induced genotoxicity in marker-heterozygous flies resulted mainly from mitotic recombination. At low concentrations, $P$. ginseng had antirecombinogenic activity that was independent of the concentration of extract used. Recombination events may promote cancer, but little is known about the ability of $P$. ginseng to inhibit such recombination or modulate DNA repair mechanisms.
\end{abstract}

Key words: antigenotoxicity, SMART, wing spot test.

Received: December 20, 2007; Accepted: March 27, 2008.

\section{Introduction}

Plant products are being increasingly used as complementary or alternative medicines for the treatment for a variety of diseases, including cancer (Meijerman et al., 2006), although in many cases there is still only limited scientific evidence for their therapeutic efficacy. The root of Panax ginseng C. A. Meyer (Araliaceae), a common plant in eastern Asia, is widely used in Chinese natural medicine (Lee et al., 2004; Yoshikawa et al., 2007). Panax ginseng is also being increasingly prescribed in Korea, Japan and Western countries for the treatment of cancer, diabetes, chronic inflammation, and neurodegenerative and cardiovascular diseases (Yun, 1996; Radad et al., 2006). Several studies have demonstrated the therapeutic potential of ginseng in the central nervous system through its ability to improve longevity (Attele et al., 1999; Li et al., 2000) and cognitive performance (Kennedy et al., 2004; Reay et al., 2005), as well as its adaptogenic properties in contributing to the equilibrium of the human body under prolonged stress (Kumar et al., 1996).

Send correspondence to Mário Antônio Spanó. Laboratório de Mutagênese, Instituto de Genética e Bioquímica, Universidade Federal de Uberlândia, Bloco D - Sala 2D52, Campus Umuarama, 38400-902 Uberlândia, MG, Brazil. E-mail: maspano@ufu.br.
Ginseng contains many physiologically important constituents that include saponins, oils and phytosterol, carbohydrates and sugars, organic acids, nitrogenous substances, amino acids and peptides, vitamins and minerals (iron, copper, zinc), and several enzymes (Hou, 1977; Attele et al., 1999). Of the various compounds isolated from ginseng roots, the ginsenosides are known to have multiple pharmacological activities (Deng and Zhang, 1991; Baek et al., 2006; Wang et al., 2007). At the doses commonly used, the dried roots and rhizomes of ginseng are not toxic to rats, dogs and humans (Radad et al., 2006).

There is increasing interest in the identification of herbal and dietary compounds that can prevent or reduce the risks of cancer or serve as therapeutic agents (Rauscher et al., 1998; Li et al., 2000). One result of these efforts is that chemoprevention has emerged as a cost-effective means of preventing mutagenesis and carcinogenesis, and as a promising approach for minimizing the adverse effects of human exposure to environmental carcinogens (PoolZobel et al., 1997; Rauscher et al., 1998).

Doxorubicin (DOX), a broad-spectrum anthracycline antibiotic, is genotoxic and carcinogenic but is still widely used as an antitumor agent for the treatment of cancer (Minotti et al., 2004). The potential usefulness of this drug 
is limited by the development of adverse effects such as cardiotoxicity and nephrotoxicity. DOX may also be involved in secondary malignancies. The main mechanisms of action proposed for DOX include the inhibition of topoisomerase II, DNA intercalation, free radical formation, reductive bioactivation of the quinine ring to a semiquinone radical, DNA alkylation and cross-linking (Gewirtz, 1999; Ramji et al., 2003; Navarro et al., 2006). These mechanisms can result in the cleavage of DNA which, if not repaired, may lead to mutations and chromosomal aberrations in tumors as well as in healthy cells (Antunes and Takahashi, 1998; Gentile et al., 1998; Islaih et al., 2005; Antunes et al., 2007; Costa and Nepomuceno, 2006; Fragiorge et al., 2007; Valadares et al., 2008).

We have used the Drosophila melanogaster (fruit fly) wing somatic mutation and recombination test (SMART) as a biological indicator of chemical genotoxicity or antigenotoxicity. This one-generation test, which is very efficient and sensitive, is based on the ability of fruit flies to metabolize certain procarcinogens to their reactive metabolites and has been used to study the genotoxicity and antigenotoxicity of various natural compounds (Idaomar et al., 2002; Laohavechvanich et al., 2006; Silva et al., 2006; Fragiorge et al., 2007; Mezzoug et al., 2007; Tellez et al., 2007; Valadares et al., 2008). The wing SMART is based on the principle that a loss of heterozygosity leads to the expression of recessive marker genes in larval imaginal disk cells, thereby yielding clones of mutant cells that can be identified as mosaic spots on the wings (Graf et al., 1984, 1998). These spots can be produced by mitotic recombination or mutations (deletions, point mutations, specific types of translocation, etc.). The analysis of two genotypes (one with structurally normal chromosomes and another with a multiply inverted balancer chromosome) allows the quantitative determination of the recombinogenic activity of genotoxic compounds (Graf et al., 1998; Spanó et al., 2001).

The identification of additional and more effective antigenotoxic compounds may contribute to the development of dietary supplements that could be useful in chemotherapy. Because the use of alternative medicines in combination with conventional therapy may increase the risk of unwanted interactions in cancer patients (Meijerman et al., 2006), in this work we used the wing SMART to investigate the possible genotoxicity of three doses of a water-soluble form of the dry root of $P$. ginseng and its ability to protect against the genotoxicity of DOX. To our knowledge the effects of ginseng on DOX genotoxicity have not yet been studied in vitro or in vivo.

\section{Materials and Methods}

\section{Chemical agents}

The water-soluble form of the dry root of $P$. ginseng C. A. Meyer (ginseng coreano, in Portuguese) was obtained from Officinal Farmácia de Manipulação (Goiânia, GO,
Brazil). Doxorubicin (DOX, Doxina ${ }^{\circledR}$ - Eurofarma Laboratórios Ltda., São Paulo, Brazil; CAS No. 23214-92-8) was obtained from Hospital de Clínicas da Universidade Federal de Uberlândia (Uberlândia, MG, Brazil) and dissolved in ultrapure water in the dark. Ultrapure water, used as a negative control, was obtained from a MilliQ system (Millipore, Vimodrone, Milan, Italy). All solutions were freshly prepared in ultrapure water immediately before use.

\section{Strains and crosses}

For the wing SMART, three strains of $D$. melanogaster [(i) the multiple wing hairs: $y ; m w h j$; (2) the flare-3: $f l r^{3} / \operatorname{In}(3 L R) T M 3$, ri $p^{p}$ sep l(3)89Aa bx ${ }^{34 e}$ e $B d^{S}$; and (iii) the ORR; flare-3: ORR; $\mathrm{flr}^{3} / \operatorname{In}(3 L R) T M 3$, ri $p^{p}$ sep l(3) $89 \mathrm{Aa} \mathrm{bx}^{34 e}$ e $\left.\mathrm{Bd}^{\mathrm{S}}\right]$, and two crosses were used. The two crosses consisted of a standard (ST) cross in which flare-3 females were mated with $m w h$ males (Graf et al., 1989) and a high bioactivation (HB) cross in which ORR; flare-3 females were mated with $m w h$ males (Graf and van Schaik, 1992). The latter cross is highly sensitive to promutagens and procarcinogens because of the increased level of cytochrome P450 present in the ORR; flare-3 strain. Both crosses produced experimental larval progeny that consisted of marker-heterozygous (MH) flies $\left(m w h+/+f l r^{3}\right)$ with phenotypically wild-type wings and balancer-heterozygous (BH) flies $\left(m w h+/+T M 3, B d^{S}\right)$ with phenotypically serrate wings. Additional information about these strains and crosses is provided elsewhere (Dapkus and Merrel, 1977; Hällström and Blanck, 1985; Graf et al., 1989; Graf and van Schaik, 1992; Saner et al., 1996).

\section{Larval feeding}

After an $8 \mathrm{~h}$ mating period, the eggs were collected from the two crosses and maintained in culture flasks containing an agar-agar base (3\% w/v) and a layer of fermenting live baker's yeast supplemented with sucrose. Third instar larvae from these eggs were collected and transferred to glass vials containing $1.5 \mathrm{~g}$ of mashed potato flakes rehydrated with $5 \mathrm{~mL}$ of a solution containing the water soluble form of the dry roots of $P$. ginseng $(2.5,5.0$ or $10.0 \mathrm{mg} / \mathrm{mL}$ ) alone or in association with DOX $(0.125 \mathrm{mg} / \mathrm{mL})$. Negative (ultrapure water) and positive (DOX $0.125 \mathrm{mg} / \mathrm{mL}$ ) controls were included in these experiments. The larvae were allowed to feed on the medium until completion of their larval life ( $\sim 48 \mathrm{~h})$. The experiments were done at $25{ }^{\circ} \mathrm{C}$ and a relative humidity of $60 \%-70 \%$.

\section{Analysis of adult flies}

Adult flies were collected and stored in $70 \%$ ethanol. The wings of MH flies were mounted on slides in Faure's solution and examined for spots by using a compound microscope at $400 \mathrm{X}$ magnification. The wings of $\mathrm{BH}$ flies were mounted and analyzed whenever a positive response was obtained in the MH progeny. Single spots resulted from point mutations, chromosomal aberrations, or recom- 
bination events, whereas twin spots $\left(m w h\right.$ and $\left.f l r^{3}\right)$ were produced by mitotic recombination between the proximal marker $\mathrm{flr}^{3}$ and the centromere of chromosome 3. Only $m w h$ single spots were observed in the wings of BH flies. The results obtained in $\mathrm{MH}$ and $\mathrm{BH}$ flies were used to assess the recombinogenic potential of the water soluble form of the dry root of $P$. ginseng and DOX (Frei et al., 1992; Graf et al., 1992; Spanó et al., 2001).

\section{Data evaluation and statistical analysis}

For statistical evaluation, the multiple-decision procedure of Frei and Würgler (1988) was used and allowed four diagnoses: + , positive; $\mathrm{w}^{+}$, weak positive; -, negative and $i$, inconclusive. The frequencies of each type of mutant clone per fly in a treated series were compared pair-wise (i.e., negative control vs. Pg; DOX alone vs. DOX plus $P g$ ) using the conditional binomial test described by Kastenbaun and Bowman (1970). For the final statistical analysis of all positive outcomes, the non-parametric MannWhitney $U$-test with $\alpha=\beta=0.05$ was used to exclude false positive results (Frei and Würgler, 1995). The frequencies of clone induction per $10^{5}$ cells were used to determine the recombinogenic activity based on the following parameters: mutation frequency $\left(F_{\mathrm{M}}\right)=$ frequency of clones in $\mathrm{BH}$ flies/frequency of clones in $\mathrm{MH}$ flies, recombination frequency $\left(F_{\mathrm{R}}\right)=1-F_{\mathrm{M}}$, frequency of the total number of spots $\left(F_{\mathrm{T}}\right)=$ total number of spots in $\mathrm{MH}$ flies (considering $m w h$ and $f l r^{3}$ spots) $/$ number of flies, frequency of mutation $=F_{\mathrm{T}}$ $\mathrm{x} F_{\mathrm{M}}$ and frequency of recombination $=F_{\mathrm{T}} \mathrm{x} F_{\mathrm{R}}$ (Santos et al., 1999; Sinigaglia et al., 2006). Based on the control-corrected spot frequencies per $10^{5}$ cells the percentage of inhibition by $P$. ginseng was calculated as (DOX alone $P$. ginseng plus DOX/DOX alone) x 100 (Abraham, 1994).

\section{Results}

Tables 1 and 2 show the wing SMART results for the chronic treatment of larvae with $P$. ginseng alone $(2.5,5.0$ or $10.0 \mathrm{mg} / \mathrm{mL}$ ) or in combination with DOX $(0.125 \mathrm{mg} / \mathrm{mL})$ using flies from ST and HB crosses, respectively. Larvae from both crosses were treated under identical conditions. Negative (ultrapure water) and positive (DOX $0.125 \mathrm{mg} / \mathrm{mL}$ ) controls were included in each experiment. For statistical evaluation, the results from flies treated with $P$. ginseng were compared with data from the corresponding negative controls, whereas the results from flies treated with $P$. ginseng plus DOX were compared with data from the corresponding positive controls. Whenever there was a positive effect on the total number of spots in the $\mathrm{MH}$ progeny, the $\mathrm{BH}$ progeny were also analyzed.

There were no significant differences in the frequency of mutant spots between flies treated with 2.5, 5.0 or $10.0 \mathrm{mg}$ of $P$. ginseng $/ \mathrm{mL}$ and the negative control in ST cross MH flies (Table 1) and HB cross MH flies (Table 2). DOX (positive control) caused significant induction of all categories of spots in both the ST and HB crosses (Tables 1 and 2).

In ST cross MH flies, simultaneous treatment with 2.5 or $5.0 \mathrm{mg}$ of $P$. ginseng $/ \mathrm{mL}$ only weakly inhibited the increase in the total number of total spots caused by DOX whereas treatment with $10 \mathrm{mg}$ of $P$. ginseng $/ \mathrm{mL}$ did not alter the frequency of mutant spots (Table 1). In HB cross MH flies, simultaneous treatment with 2.5 or $10.0 \mathrm{mg}$ of $P$. ginseng $/ \mathrm{mL}$ reduced the total number of spots produced by DOX alone (Table 2). The frequency of mutant spots produced by DOX was not altered by simultaneous treatment with 2.5 or $5.0 \mathrm{mg}$ of $P$. ginseng $/ \mathrm{mL}$ in ST cross BH flies (Table 1), or 2.5 or $10.0 \mathrm{mg}$ of $P$. ginseng $/ \mathrm{mL}$ in HB cross BH flies (Table 2). Thus, $P$. ginseng did not interfere with the frequencies of DOX-induced spots of mutational (genic and chromosomal) origin.

The frequencies of clone induction per $10^{5}$ cells in $\mathrm{MH}$ and $\mathrm{BH}$ flies treated with DOX alone or with $P$. ginseng plus DOX were used to assess the mutagenic and recombinogenic potential of $P$. ginseng. The genotoxicity in $\mathrm{MH}$ flies was attributable mainly to mitotic recombination. The dry root of $P$. ginseng had antirecombinogenic activity that was not dose-dependent.

\section{Discussion}

The wing SMART is rapid, sensitive and inexpensive assay for investigating the mutagenic and recombinogenic properties of chemicals, natural products and complex mixtures. This assay is also suitable for studying the mutagenic, antimutagenic and recombinogenic activities of drugs during multi-drug therapy (Graf et al., 1984; Spanó et al., 2001).

In this study, we examined the effects of three concentrations of $P$. ginseng $(2.5,5.0$ or $10.0 \mathrm{mg} / \mathrm{mL})$ in the wing SMART. Panax ginseng alone was not genotoxic in the ST and HB crosses. Simultaneous treatment with $P$. ginseng reduced the total number of spots produced by DOX in ST cross and HB cross MH flies, although the concentrations required for this varied between the crosses.

DOX was studied here because of its widespread use in cancer chemotherapy. A single concentration of DOX $(0.125 \mathrm{mg} / \mathrm{mL})$ was used in the wing SMART and significantly increased the number of mutant single spots and twin spots in ST and HB crosses. In addition to its mutagenic activity, DOX also has recombinogenic activity so that the frequency of twin spots reflected DOX-induced somatic recombination. These findings agree with other reports and show that DOX selectively induces homologous recombination when compared with mutational events in $D$. melanogaster somatic cells (Lehmann et al., 2003; Costa and Nepomuceno, 2006; Fragiorge et al., 2007; Valadares et al., 2008).

The HB cross has constitutively high levels of cytochrome P450 and is characterized by a high sensitivity to promutagens and procarcinogens (Spanó et al., 2001). 


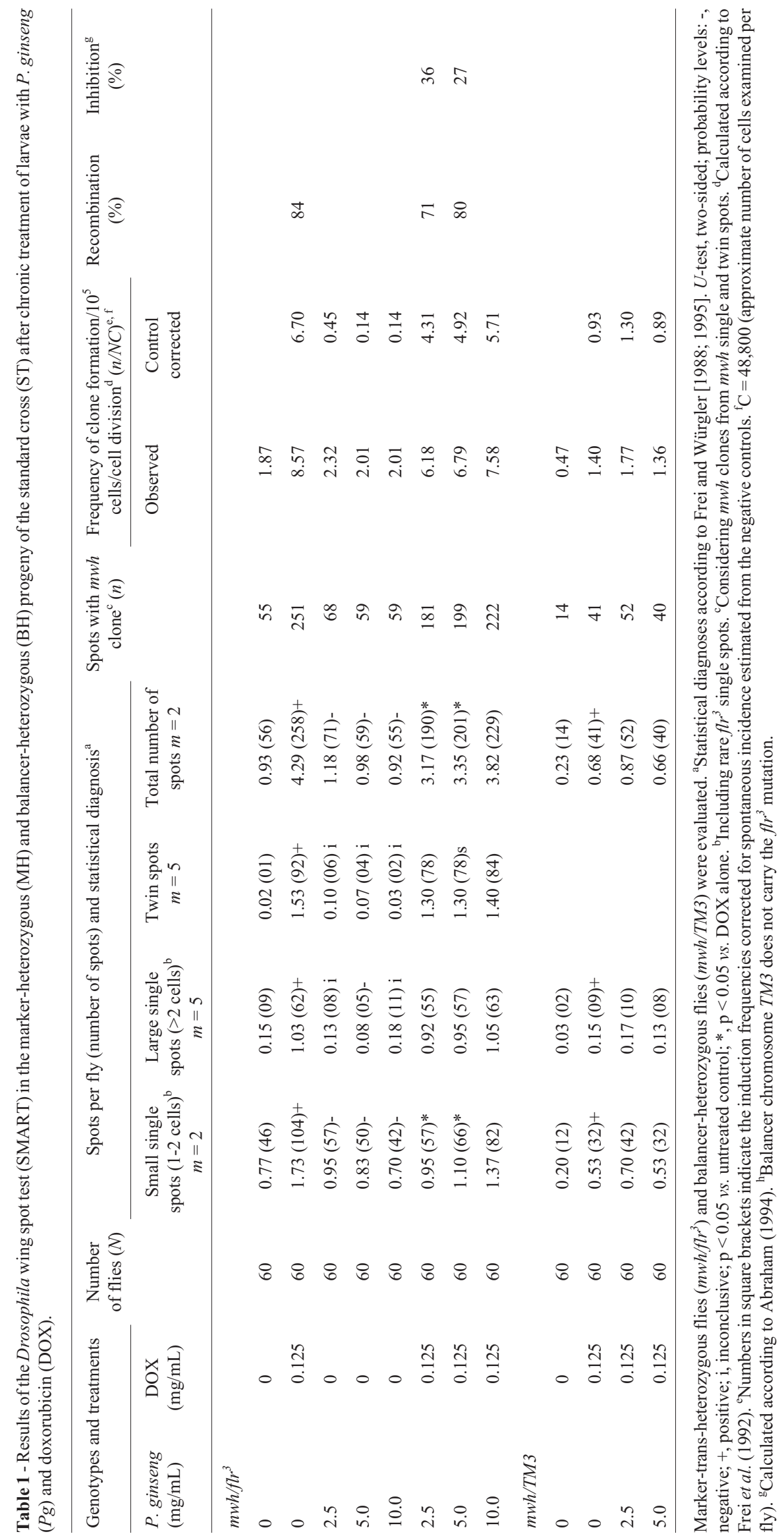




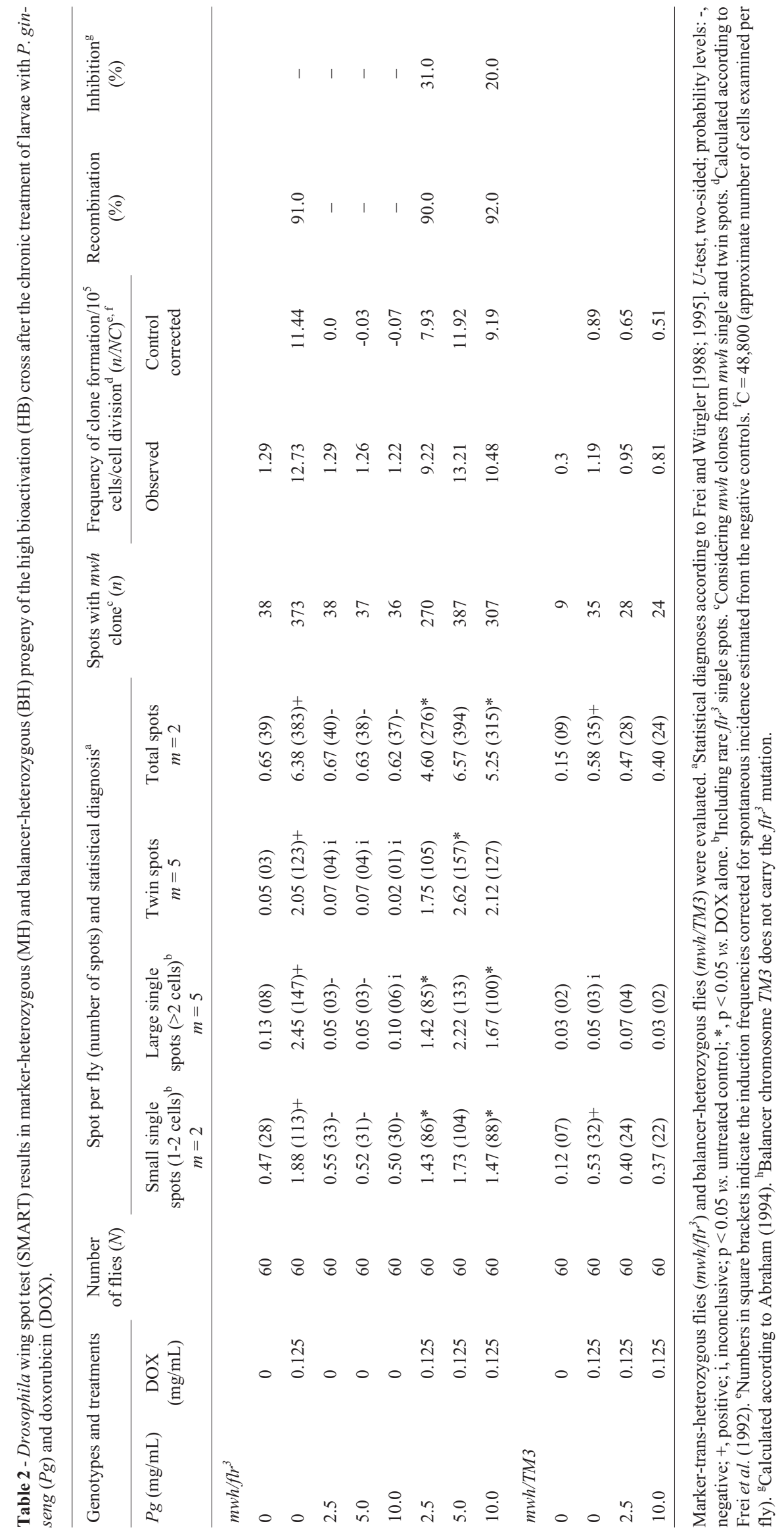


Comparison of the results obtained with the ST and HB crosses showed that the elevated cytochrome P450 activity in HB flies influenced the genotoxicity of DOX and that of the combined treatments, with a greater frequency of mutant spots in these flies, as also reported by Valadares et al. (2008). The greater genotoxicity of DOX in HB flies probably reflects the rapid one-electron reduction of this compound to its semiquinone free radical by cytochrome P450 (Goeptar et al., 1993).

Many herbal and dietary products modulate cytochrome P450 activity. Gurley et al. (2002) used single-time point phenotypic metabolic ratios to determine whether long-term supplementation of St John's wort, garlic oil, $P$. ginseng and Ginkgo biloba affected CYP1A2, CYP2D6, CYP2E1 and CYP3A4 activities in humans; no significant effect was observed for $P$. ginseng. In agreement with this, Gurley et al. (2005) observed that the concomitant ingestion of $P$. ginseng with prescription medications in elderly patients resulted in only slight inhibition (7\%) of CYP2D6 activity.

Ginseng extract significantly decreases DNA synthesis and increases the rate of DNA excision repair synthesis in V79 Chinese hamster lung cells (Rhee et al., 1991), in addition to its ability to attenuate inflammation-mediated carcinogenesis (Hofseth and Wargovich, 2007). These mechanisms can reduce tumor growth and improve the prognosis in cancer patients (Wang et al., 2007). The beneficial effects of ginseng and its main constituents during chemotherapy are probably related to their ability to minimize the adverse effects of antineoplastic drugs. Recent findings in vivo and in vitro have shown that ginseng partially protects against DOX-induced testicular toxicity (Kang et al., 2002), significantly attenuates the effects of DOX-induced heart failure in rats (You et al., 2005), and reduces cisplatin-induced nephrotoxicity in cultured renal proximal tubular epithelial cells (Baek et al., 2006). In contrast, little is known about the effects of ginseng and its compounds when administered in combination with chemotherapeutic drugs.

Dietary supplementation of ginseng protects against oxidative damage in vitro and in vivo, from acute oxidative stress in cardiomyocytes to heart perfusion injury (MaffeiFacino et al., 1999; Shao et al., 2004). Yance and Sagar (2006) reported that $P$. ginseng has antiangiogenic activity and anticancer activities that are mediated by multiple interdependent processes, including changes in gene expression, signal processing and enzymatic activities. Although the mechanisms of action of the more than 60 ginsenosides isolated from Panax species remain poorly understood, studies of these compounds and their effects on tumor cells are of interest since several ginsenosides efficiently inhibit cell growth and the proliferation of human cancer cell lines (Wang et al., 2007).

Total ginseng extracts or aqueous fractions of $P$. ginseng show antimutagenic effects that include a reduction in the frequency of radiation-induced DNA breaks in murine lymphocytes and protection against ${ }^{137} \mathrm{Cs}$-induced micronuclei in human lymphocytes (Rhee et al., 1991; Kim et al., 1996; Lee et al., 2004). Ginseng-treated Swiss white mice show a significant reduction in the frequencies of chromosomal aberrations and micronuclei induced by benzo[a]pyrene (Panwar et al., 2005). Ginsan, which itself is not mutagenic, decreases the frequency of micronucleated polychromatic erythrocytes induced by gamma radiation in bone marrow cells of C57BL/6 male mice (Ivanova et al., 2006). Similarly, the ginsenoside $\mathrm{Rh}_{2}$ enhances the antitumor activity and decreases the genotoxicity of cyclophosphamide in mice (Wang et al., 2006). Ginseng has powerful antioxidant (Cho et al., 2008) and antimutagenic (Geetha et al., 2006; Ivanova et al., 2006) properties, although the mechanisms of these protective effects remain to be elucidated. Geetha et al. (2006) reported that ginseng extracts protected against $\mathrm{H}_{2} \mathrm{O}_{2}$-induced mutagenesis in Salmonella typhimurium strain TA100, and against mutagenesis produced by 4-nitroquinoline-N-oxide in S. typhimurium strains TA98 and TA100 in the Ames test; however, the extract was unable to inhibit the damage induced by tert-butyl hydroperoxide in strain TA102 which is highly sensitive to reactive oxygen species. The authors concluded that the protection provided by the ginseng extract against 4-nitroquinoline-N-oxide and $\mathrm{H}_{2} \mathrm{O}_{2}$-induced mutagenicity in strains TA98 and TA100 was attributable mainly to the extracts ability to promote DNA repair rather than its antioxidant effects.

Our results indicate that $P$. ginseng is not genotoxic in somatic cells of $D$. melanogaster, and that at low concentrations it protects against the genotoxicity of DOX. Inhibitors of mutagenesis often act through multiple mechanisms or can interact with other inhibitors (De Flora and Ramel, 1988). The mechanisms by which $P$. ginseng protects cells against DOC-induced genotoxicity were not examined here but could involve direct interaction of the extract constituents with DOX, resulting in an antimutagenic effect, and/or an antioxidant action through radical scavenging or the activation of intracellular antioxidant enzymes. Although homologous recombination causes rearrangements of DNA that can promote cancer, little was known about the ability of $P$. ginseng to inhibit recombination or modulate DNA repair mechanisms. More data are required on the doseresponse relationship of $P$. ginseng and the potential toxicities of combinations with chemotherapeutic drugs or radiation before this product can be recommended for cancer therapy.

\section{Acknowledgments}

This work was supported by the Conselho Nacional de Desenvolvimento Científico e Tecnológico (CNPq), Coordenação de Aperfeiçoamento de Pessoal de Nível Superior (CAPES), Fundação de Amparo à Pesquisa do Estado 
de Minas Gerais (FAPEMIG) and the Universidade Federal de Uberlândia (UFU).

\section{References}

Abraham SK (1994) Antigenotoxicity of coffee in the Drosophila assay for somatic mutation and recombination. Mutagenesis 9:383-386.

Antunes LMG and Takahashi CS (1998) Effects of high doses of vitamins $\mathrm{C}$ and $\mathrm{E}$ against doxorubicin-induced chromosomal damage in Wistar rat bone marrow cells. Mutat Res 419:137-143.

Antunes LMG, Bueno RBL, Dias FL and Bianchi MLP (2007) Acetylsalicylic acid exhibits anticlastogenic effects on cultured human lymphocytes exposed to doxorubicin. Mutat Res 626:155-161.

Attele AS, Wu JA and Yuan CS (1999) Ginseng pharmacology: Multiple constituents and multiple actions. Biochem Pharmacol 58:1685-1693.

Baek SH, Piao XL, Lee UJ, Kim HY and Park JH (2006) Reduction of cisplatin-induced nephrotoxicity by ginsenosides isolated from processed ginseng in cultured renal tubular cells. Biol Pharm Bull 29:2051-2055.

Cho EJ, Piao XL, Jang MH, Baek SH, Kim HY, Kang KS, Kwon SW and Park JH (2008) The effect of steaming on the free amino acid contents and antioxidant activity of Panax ginseng. Food Chem 107:876-882.

Costa WF and Nepomuceno JC (2006) Protective effects of a mixture of antioxidant vitamins and minerals on the genotoxicity of doxorubicin in somatic cells of Drosophila melanogaster. Environ Mol Mutagen 47:18-24.

Dapkus D and Merrel DJ (1977) Chromosomal analysis of DDTresistance in a long-term selected population of Drosophila melanogaster. Genetics 87:685-697.

De Flora S and Ramel C (1988) Mechanisms of inhibitors of mutagenesis and carcinogenesis. Classification and overview. Mutat Res 202:285-306.

Deng HL and Zhang JT (1991) Anti-lipid peroxidative effect of ginsenoside Rb1 and Rg1. Chin Med J 104:395-398.

Fragiorge EJ, Spanó MA and Antunes LMG (2007) Modulatory effects of the antioxidant ascorbic acid on the direct genotoxicity of doxorubicin in somatic cells of Drosophila melanogaster. Genet Mol Biol 30:449-455.

Frei H and Würgler FE (1988) Statistical methods to decide whether mutagenicity test data from Drosophila assays indicate a positive, negative, or inconclusive result. Mutat Res 203:297-308.

Frei H and Würgler FE (1995) Optimal experimental design and sample size for the statistical evaluation of data from somatic mutation and recombination test (SMART) in Drosophila. Mutat Res 334:247-258.

Frei H, Clements J, Howe D and Würgler FE (1992) The genotoxicity of the anti-cancer drug mitoxantrone in somatic and germ cells of Drosophila melanogaster. Mutat Res 279:2133.

Geetha T, Saini A and Kaur IP (2006) Ginseng extract exhibits antimutagenic activity against induced mutagenesis in various strains of Salmonella typhimurium. Indian J Exp Biol 44:838-841.
Gentile JM, Rahimi S, Zwiesler J, Gentile GJ and Ferguson LR (1998) Effect of selected antimutagens on the genotoxicity of antitumor agents. Mutat Res 402:289-298.

Gewirtz DA (1999) A critical evaluation of the mechanisms of action proposed for the antitumor effects of the anthracycline antibiotics adriamycin and daunorubicin. Biochem Pharmacol 57:727-741.

Goeptar AR, Koppele JMT, Lamme EK, Pique JM and Vermeulen NPE (1993) Cytochrome P450-2B1-mediated oneelectron reduction of adriamycin - A study with rat-liver microsomes and purified enzymes. Mol Pharmacol 44:1267-1277.

Graf U and van Schaik N (1992) Improved high bioactivation cross for the wing somatic mutation and recombination test in Drosophila melanogaster. Mutat Res 271:59-67.

Graf U, Frei H, Kägi A, Katz AJ and Würgler FE (1989) Thirty compounds tested in the Drosophila wing spot test. Mutat Res 222:359-373.

Graf U, Abraham SK, Guzmán-Rincón J and Würgler FE (1998) Antigenotoxicity studies in Drosophila melanogaster. Mutat Res 402:203-209.

Graf U, Heo O and Olvera-Ramirez O (1992) The genotoxicity of chromium (VI) oxide in the wing spot test of Drosophila melanogaster is over $90 \%$ due to mitotic recombination. Mutat Res 266:197-203.

Graf U, Würgler FE, Katz AJ, Frei H, Juon H, Hall CB and Kale PG (1984) Somatic mutation and recombination test in Drosophila melanogaster. Environ Mutagen 6:153-188.

Gurley BJ, Gardner SF, Hubbard MA, Williams DK, Gentry WB, Cui Y and Ang CYW (2002) Cytochrome P450 phenotypic ratios for predicting herb-drug interactions in humans. Clin Pharmacol Ther 72:276-287.

Gurley BJ, Gardner SF, Hubbard MA, Williams DK, Gentry WB, Cui Y and Ang CYW (2005) Clinical assessment of effects of botanical supplementation on cytochrome P450 phenotypes in the elderly: St John's wort, garlic oil, Panax ginseng and Ginkgo biloba. Drugs Aging 22:525-539.

Hällström I and Blank A (1985) Genetic regulation of the cytochrome P-450 system in Drosophila melanogaster. I. Chromosomal determination of some cytochrome P-450dependent reactions. Chem Biol Interact 56:151-171.

Hofseth LJ and Wargovich MJ (2007) Inflammation, cancer, and targets of ginseng. J Nutr 137:183S-185S.

Hou JP (1977) The chemical constituents of ginseng plants. Comp Med East West 5:123-145.

Idaomar M, El-Hamss R, Bakkali F, Mezzouq N, Zhiri A, Baudoux D, Munoz-Serrano A, Liemans V and Alonso-Moraga A (2002) Genotoxicity and antigenotoxicity of some essential oils evaluated by wing spot test of Drosophila melanogaster. Mutat Res 513:61-68.

Islaih M, Halstead BW, Kadura IA, Reid-Hubbard JL, Flick F, Altizer JL, Thom DJ, Monteith DK, Newton RK and Watson DE (2005) Relationships between genomic, cell cycle, and mutagenic responses of TK6 cells exposed to DNA damaging chemicals. Mutat Res 578:100-116.

Ivanova T, Han Y, Son HJ, Yun YS and Song JY (2006) Antimutagenic effect of polysaccharide ginsan extracted from Panax ginseng. Food Chem Toxicol 44:517-521.

Kang J, Lee Y, No K, Jung E, Sung J, Kim Y and Nam S (2002) Ginseng intestinal metabolite-I (GIM-I) reduces doxoru- 
bicin toxicity in the mouse testis. Reprod Toxicol 16:291298.

Kastenbaum MA and Bowman KO (1970) Tables for determining the statistical significance of mutation frequencies. Mutat Res 9:527-549.

Kennedy DO, Haskell CF, Wesnes KA and Scholey AB (2004) Improved cognitive performance in human volunteers following administration of guarana (Paullinia cupana) extract: Comparison and interaction with Panax ginseng. Pharmacol Biochem Behav 79:401-411.

Kim YH, Park KH and Rho HM (1996) Transcriptional activation of the $\mathrm{Cu}, \mathrm{Zn}$-superoxide dismutase gene through the AP2 site by ginsenoside $\mathrm{Rb} 2$ extracted from a medicinal plant, Panax ginseng. J Biol Chem 271:24539-24543.

Kumar R, Grover SK, Divekar HM, Gupta AK, Shvam R and Srivastava KK (1996) Enhanced thermogenesis in rats by Panax ginseng, multivitamins and minerals. Int $\mathrm{J}$ Biometerol 39:187-191.

Laohavechvanich P, Kangsadalampai K, Tirawanchai N and Ketterman AJ (2006) Effect of different Thai traditional processing of various hot chili peppers on urethane-induced somatic mutation and recombination in Drosophila melanogaster: Assessment of the role of glutathione transferase activity. Food Chem Toxicol 44:1348-1354.

Lee TK, Alisson RR, O'Brien KF, Khazanie PG, Johnke RM, Brown R, Bloch RM, Tate ML, Dobbs LJ and Kragel PJ (2004) Ginseng reduces the micronuclei yield in lymphocytes after irradiation. Mutat Res 557:75-84.

Lehmann M, Franco A, Vilar KDSP, Reguly ML and de Andrade HHR (2003) Doxorubicin and two of its analogues are preferential inducers of homologous recombination compared with mutational events in somatic cells of Drosophila melanogaster. Mutat Res 539:167-175.

Li W, Wanibuchi H, Salim EI, Wei M, Yamamoto S, Nishino H and Fukushima S (2000) Inhibition by ginseng of 1,2-dimethylhydrazine induction of aberrant crypt foci in the rat colon. Nutr Cancer 36:66-73.

Maffei-Facino R, Carini M, Aldini G, Berti F and Rossoni G (1999) Panax ginseng administration in the rat prevents myocardial ischemia-reperfusion damage induced by hyperbaric oxygen: Evidence for an antioxidant intervention. Planta Med 65:614-619.

Meijerman I, Beijnen JH and Schellens JHM (2006) Herb-drug interactions in oncology: Focus on mechanisms of induction. Oncologist 11:742-752.

Mezzoug N, Elhadri A, Dallouh A, Amkiss S, Skali NS, Abrini J, Zhiri A, Baudoux D, Diallo B, El Jaziri A, et al. (2007) Investigation of the mutagenic and antimutagenic effects of Origanum compactum essential oil and some of its constituents. Mutat Res 629:100-110.

Minotti G, Menna P, Salvatorelli E, Cairo G and Gianni L (2004) Anthracyclines: Molecular advances and pharmacologic developments in antitumor activity and cardiotoxicity. Pharmacol Rev 56:185-229.

Navarro R, Busnadiego I, Ruiz-Larrea MB and Ruiz-Sanz JI (2006) Superoxide anions are involved in doxorubicininduced ERK activation in hepatocyte cultures. Ann NY Acad Sci 1090:419-428.

Panwar M, Samarth R, Kumar M, Yoon WJ and Kumar A (2005) Inhibition of benzo(a)pyrene induced lung adenoma by
Panax ginseng extract, EFLA400, in Swiss albino mice. Biol Pharm Bull 28:2063-2067.

Pool-Zobel BL, Bub A, Muller H, Wollowsky I and Rechkemmer G (1997) Consumption of vegetables reduces genetic damage in humans: First results of a human intervention trial with carotenoid-rich foods. Carcinogenesis 18:1847-1850.

Radad K, Gille G, Liu L and Rausch W-D (2006) Use of ginseng in medicine with emphasis on neurodegenerative disorders. J Pharmacol Sci 100:175-186.

Ramji S, Lee C, Inaba T, Patterson AV and Riddick DS (2003) Human NADPH-cytochrome P450 reductase overexpression does not enhance the aerobic cytotoxicity of doxorubicin in human breast cancer cell lines. Cancer Res 63:6914-6919.

Rauscher R, Edenharder R and Platt KL (1998) In vitro antimutagenic and in vivo anticlastogenic effects of carotenoids and solvent extracts from fruits and vegetables rich in carotenoids. Mutat Res 413:129-142.

Reay JL, Kennedy DO and Scholey AB (2005) Single doses of Panax ginseng (G115) reduce blood glucose levels and improve cognitive performance during sustained mental activity. J Psychopharmacol 19:357-365.

Rhee YH, Ahn JH, Choe J, Kang KW and Joe C (1991) Inhibition of mutagenesis and transformation by root extracts of Panax ginseng in vitro. Planta Med 57:125-128.

Saner C, Weibel B, Würgler FE and Sengstag C (1996) Metabolism of promutagens catalyzed by Drosophila melanogaster CYPA2 enzyme in Saccharomyces cerevisae. Environ Mol Mutagen 27:46-58.

Santos JH, Graf U, Reguly ML and Andrade HHR (1999). The synergistic effects of vanillin on recombination predominate over its antimutagenic action in relation to MMC-induced lesions in somatic cells of Drosophila melanogaster. Mutat Res 444:355-365.

Shao ZH, Xie JT, Vanden Hoek TL, Mehendale S, Aung H, Li CQ, Qin Y, Schumacker PT, Becker LB and Yuan CS (2004) Antioxidant effects of American ginseng berry extract in cardiomyocytes exposed to acute oxidant stress. Biochim Biophys Acta 1670:165-171

Silva LP, Costa-Cruz JM, Spanó MA and Graf U (2006) Genotoxicity of vesicular fluid and saline extract of Taenia solium metacestodes in somatic cells of Drosophila melanogaster. Environ Mol Mutagen 47:247-253.

Sinigaglia M, Lehmann M, Baumgardt P, Amaral VS, Dihl RR, Reguly ML and Andrade HHR (2006) Vanillin as a modulator agent in SMART test: Inhibition in the steps that precede $N$-methyl- $N$-nitrosourea-, $N$-ethyl- $N$-nitrosourea-, ethylmethanesulphonate- and bleomycin-genotoxicity. Mutat Res 607:225-230.

Spanó MA, Frei H, Würgler FE and Graf U (2001) Recombinogenic activity of four compounds in the standard and high bioactivation crosses of Drosophila melanogaster in the wing spot test. Mutagenesis 16:385-394.

Tellez MGO, Rodriguez HB, Olivares GQ, Sortibran ANC, Cetto AA and Rodriguez-Arnaiz R (2007) Phytotherapeutic extract of Equisetum myriochaetum is not genotoxic either in the in vivo wing somatic test of Drosophila or in the in vitro human micronucleus test. J Ethnopharmacol 111:182-189.

Valadares BLB, Graf U and Spanó MA (2008) Inhibitory effects of water extract of propolis on doxorubicin-induced somatic 
mutation and recombination in Drosophila melanogaster. Food Chem Toxicol 46:1103-1110.

Wang W, Zhao Y, Rayburn ER, Hill DL, Wang H and Zhang R (2007) In vitro anti-cancer activity and structure-activity relationships of natural products isolated from fruits of Panax ginseng. Cancer Chemother Pharmacol 59:589-601.

Wang Z, Zheng Q, Liu K, Li G and Zheng R (2006) Ginsenoside $\mathrm{Rh} 2$ enhances antitumour activity and decreases genotoxic effect of cyclosphophamide. Basic Clin Pharmacol Toxicol 98:411-415.

Yance Jr DR and Sagar SM (2006) Targeting angiogenesis with integrative cancer therapies. Integr Cancer Ther 5:9-29.

Yoshikawa M, Sugimoto S, Nakamura S and Matsuda H (2007) Medicinal flowers. XI. Structures of new dammarane-type triterpene diglycosides with hydroperoxide group from flower buds of Panax ginseng. Chem Pharm Bul 55:571576.

You J-S, Huang H-F and Chang Y-L (2005) Panax ginseng reduces adriamycin-induced heart failure in rats. Phytother Res 19:1018-1022.

Yun TK (1996) Experimental and epidemiological evidence of cancer preventive effects of Panax ginseng C.A. Meyer. Nutr Res 54:71-81.

Associate Editor: Catarina S. Takahashi

License information: This is an open-access article distributed under the terms of the Creative Commons Attribution License, which permits unrestricted use, distribution, and reproduction in any medium, provided the original work is properly cited. 